\title{
IL-1 $\beta$ impedes the chondrogenic differentiation of synovial fluid mesenchymal stem cells in the human temporomandibular joint
}

\author{
WENJING LIU ${ }^{1,2 *}$, YANGPENG SUN ${ }^{1 *}$, YIQING HE $^{1}$, HONG ZHANG $^{1}$, \\ YOUHUA ZHENG $^{1}$, YU YAO ${ }^{1}$ and ZHIGUANG ZHANG ${ }^{1}$
}

\begin{abstract}
${ }^{1}$ Guanghua School of Stomatology, Hospital of Stomatology, Guangdong Provincial Key Laboratory of Stomatology, Sun Yat-sen University; ${ }^{2}$ Zhongshan School of Medicine, Sun Yat-sen University, Guangzhou, Guangdong 510055, P.R. China
\end{abstract}

Received October 28, 2015; Accepted December 7, 2016

DOI: $10.3892 /$ ijmm.2016.2832

\begin{abstract}
Mesenchymal stem cell-based therapy has great therapeutic potential for temporomandibular joint (TMJ) cartilage repair. However, the behavior of mesenchymal stem cells in the inflammatory milieu following their delivery remains poorly understood. Synovial fluid-derived mesenchymal stem cells (SFMSCs) are a promising resource for TMJ cartilage repair, as they are easily obtained from patients with TMJ disorders (TMD). In this study, we obtained SFMSCs from patients with TMD and expanded them in vitro; we then stimulated the cells with interleukin (IL)-8, IL-1 $\beta$, IL-6, IL-10, tumor necrosis factor (TNF)- $\alpha$ and IL-12p. The cells expressed CD90, CD44, CD105 and CD73, and were negative for CD45, CD34, CD11b, CD19 and HLA-DR. They could be induced to differentiate into osteogenic, chondrogenic, adipogenic and neurogenic lineages in vitro. Only the levels of IL-6 and IL-8 were upregulated significantly following stimulation with IL-8, IL-1 $\beta$, IL-6, IL-10, TNF- $\alpha$ and IL-12p. Furthermore, IL-6 and IL-8 expression was driven mainly by IL-1 $\beta$-dependent nuclear factor- $\kappa \mathrm{B}(\mathrm{NF}-\kappa \mathrm{B})$ pathway activation, and was independent of IL-8, IL-6, IL-10, TNF- $\alpha$ and IL-12p. IL-6 and IL-8 expression was inhibited completely by treatment with the $\mathrm{NF}-\kappa \mathrm{B}$ inhibitor,
\end{abstract}

Correspondence to: Dr Zhiguang Zhang or Dr Yangpeng Sun, Guanghua School of Stomatology, Hospital of Stomatology, Guangdong Provincial Key Laboratory of Stomatology, Sun Yat-sen University, 56 Lingyuan West Road, Guangzhou, Guangdong 510055, P.R. China

E-mail: kouqiangzzg@hotmail.com

E-mail: sunyp@mail2.sysu.edu.cn

${ }^{*}$ Contributed equally

Abbreviations: TMJ, temporomandibular joint; MSCs, mesenchymal stem cells; TMD, temporomandibular joint disorders; SFMSCs, synovial fluid-derived mesenchymal stem cells; MPC, mesenchymal progenitor cell; OA, osteoarthritis; RA, rheumatoid arthritis; NF- $\kappa$ B, nuclear factor- $\kappa \mathrm{B}$; DI, dysfunction index

Key words: mesenchymal stem cells, cytokines, arthritis, temporomandibular, synovial fluid
BAY11-7082. SRY-box 9 (SOX9) was downregulated and matrix metalloproteinase $(M M P) 13$ was upregulated upon chondrogenic differentiation induced in the cells also exposed to IL-1 $\beta$. Sulfated glycosaminoglycan production was also reduced upon chondrogenic differentiation in the presence of IL-6, but not IL-8. Thus, IL-1 $\beta$ in the inflammatory milieu is crucial in regulating SFMSCs. In doing so, IL-1 $\beta$ impedes the chondrogenic differentiation of SFMSCs. The upregulation of IL-6 and NF- $\kappa$ B pathway activation also contribute to this biological behavior. The findings of our study indicate the potential adverse effects of IL-1 $\beta$ on the chondrogenic differentiation of SFMSCs, and may thus provide new insight into the pathogenesis of TMD.

\section{Introduction}

Temporomandibular joint disorder (TMD) is a common disease of the stomatognathic system. It is a degenerative disease, accompanied by internal derangement or osteoarthritis (OA), which is characterized by progressive articular cartilage destruction and decreased physical capabilities. Underlying these symptoms is the limited self-regenerating capacity of cartilage. Certain drugs, such as etanercept, infliximab and adalimumab, have been used clinically to treat TMD following the failure of traditional injection with corticosteroids or hyaluronic acid. However, a substantial proportion of patients still fail to respond to these biological therapies (1).

Mesenchymal stem cells (MSCs) are increasingly being considered attractive biological therapeutic agents for the treatment of inflammatory diseases and for the stimulation of tissue regeneration. They possess multi-differentiation potential and can be isolated from various human tissues, such as the bone marrow, adipose tissue, the synovium and periosteum. Among these sources, synovial fluid plays an important role in regulating temporomandibular joint (TMJ) physiology. Jones et al (2) were the first to identify MSCs in the synovial fluid of swollen osteoarthritic knee joints. These cells may originate from the MSCs in synovial tissue (3), as both populations express similar cell surface markers (4). Whereas the majority of subsequent studies have focused on large joints, information regarding synovial fluid-derived MSCs (SFMSCs) in the TMJ is limited. Koyama et al demonstrated that human pluripotent cells can be isolated from the synovial fluid of patients with TMD (5). Analogous to MSCs that are isolated from the fragments of syno- 
vial tissue and synovial fluid, we hypothesized that the SFMSCs most likely originate from the disrupted intimal synovium (6). SFMSCs of the human TMJ can be obtained by arthrocentesis, which is a commonly used and less invasive method compared with arthroscopy or open operation to obtain sections of the synovium. Therefore, these cells constitute a promising resource for cell-directed articular cartilage repair.

Both the genetic background of MSCs and the local inflammatory milieu may affect the ability of MSCs to modulate disease activity in vitro $(7,8)$. The number of SFMSCs reportedly increases in early human $\mathrm{OA}$, and this increase correlates with cartilage degeneration and the severity of OA in the knee (9-11). Thus, these cells may play a potential role in joint homeostasis. Neidhart et al (12) found that adherent synovial fluid cells derived from patients with rheumatoid arthritis (RA) mediated cartilage destruction, independent of the accompanying synovial tissue hyperplasia. Heldens et al (13) demonstrated that human MSC chondrogenesis was inhibited in a diseased joint environment or upon treatment with pro-inflammatory cytokines. In another study, the amount of chondrogenic differentiation of mesenchymal progenitor cell (MPC) pellets in operated knees was significantly lower than that observed in control subjects. Additional treatment with interleukin (IL)-1 $\beta$ also affected the degree of chondrogenic differentiation in cell pellets derived from bone marrow-derived MSCs (14). To the best of our knowledge, however, the effect of the inflammatory milieu on SFMSCs delivered to human TMJs remains poorly understood. To address this issue, in this study, we characterized the inflammatory factors that are secreted by SFMSCs following stimulation with IL-8, IL-1 $\beta$, IL-6, IL-10, tumor necrosis factor (TNF)- $\alpha$ and IL-12p in vitro. We found that the expression of only IL- 6 and IL-8 increased significantly upon IL-1 $\beta$ stimulation, and that this was independent of IL-8, IL-6, IL-10, TNF- $\alpha$ and IL-12p stimulation.

IL-1 $\beta$ is a pivotal pro-inflammatory cytokine that mediates a variety of host defense processes, including inflammation and cellular response to injury, which can also lead to joint destruction if left unchecked (15). The level of IL-1 $\beta$ is significantly higher in the synovial fluid from patients with TMD and chondral damage than in the synovial fluid from asymptomatic volunteers (16-18). IL- $1 \beta$ reduces the expression of type II collagen and aggrecan by the increased secretion of matrix metalloproteinases (MMPs) by chondrocytes (19). This requires the activation of the nuclear factor $-\kappa \mathrm{B}(\mathrm{NF}-\kappa \mathrm{B})$ pathway, which has been described as the link between inflammation and joint cartilage degeneration in OA (20-22). In this study, we further evaluated the chondrogenic differentiation potency and intracellular signaling pathways that are mediated by IL-1 $\beta$ in SFMSCs.

\section{Materials and methods}

Ethics statement. This study was approved by the Institutional Ethics Board of the Hospital of Stomatology, Sun Yat-sen University, Guangzhou, China. Written informed consent was obtained from the sample providers prior to participation in this study.

Assay of inflammatory cytokines in the TMJ. Synovial fluid samples were obtained from 19 patients with TMD (19 laterals) during arthrocentesis of the TMJ. These patients were aged between 16 and 57 years; 16 were female and 3 were male, and all were free of other systemic diseases. The patients with TMD were evaluated using the dysfunction index (DI) described in the study by Fricton JR and Schiffman (23). The synovial fluid samples were withdrawn with $2 \mathrm{ml}$ of lidocaine (containing $25 \%$ vitamin $B_{12}$ ). We measured the levels of IL- 8 , IL-1 $\beta$, IL-6, IL-10, TNF- $\alpha$ and IL-12p in the synovial fluid samples with a BD Cytometric Bead Array (CBA) Human Soluble Protein Master Buffer kit (Human Inflammatory Cytokine kit; Cat. no. 551811; BD Biosciences, Bedford, MA, USA). The cytokine concentrations in the synovial fluid were calculated using the following formula: $\mathrm{C}=\mathrm{Casp} /\left[\left(\mathrm{OD}_{\mathrm{inj}}-\mathrm{OD}_{\mathrm{asp}}\right) / \mathrm{OD}_{\mathrm{inj}}\right]$, $\mathrm{C}_{\text {asp }}$ refers to the levels of IL- 8 , IL- $1 \beta$, IL-6, IL-10, TNF- $\alpha$ and IL-12p in the synovial fluid samples; $\mathrm{OD}_{\mathrm{inj}}$ refers to the optical density of lidocaine containing $25 \%$ vitamin $B_{12}$ before injection; $\mathrm{OD}_{\text {asp }}$ refers to the optical density of lidocaine containing $25 \%$ vitamin $B_{12}$ after injection, as previously described (16).

Human SFMSC isolation and expansion. The collected synovial fluid samples were centrifuged at $300 \mathrm{x}$ g for $5 \mathrm{~min}$ at room temperature, and the supernatant was used in the inflammatory cytokine assay. The sediment was then cultured with complete culture medium $[\alpha$ minimum essential medium supplemented with $10 \%$ fetal bovine serum and 1X GlutaMAX (both from Gibco, Grand Island, NY, USA) at $37^{\circ} \mathrm{C}$ in a $5 \% \mathrm{CO}_{2}$ incubator. Portions of the cells from each sample were mixed and expanded in a monolayer culture for further experimentation. The cells were passaged at a density of 500 cells $/ \mathrm{cm}^{2}$.

Surface antigen identification. Surface markers, including CD90 (1:20; Cat. no. 562245; BD Biosciences), CD105 (1:11; Cat. no. 130-094-941; Miltenyi Biotec, Begisch Gladbach, Germany), CD73 (1:20), CD44 (1:20), and CD45/CD34/CD11b/CD19/HLA-DR (1:20) (Cat. no. 562245; all from BD Biosciences), were detected using an FC500 flow cytometer and MXP software, and the data were analyzed using CXP software (both from Beckman Coulter, Brea, CA, USA).

Osteogenic differentiation. The SFMSCs were seeded in 12 -well plates at a density of 5,000 cells $/ \mathrm{cm}^{2}$. Following adherence, the complete culture medium was replaced with osteogenic induction medium consisting of H-DMEM, $10 \%$ fetal bovine serum (FBS) (both from Gibco), $10 \mathrm{mM}$ sodium $\beta$-glycerophosphate (Santa Cruz Biotechnology, Inc., Santa Cruz, CA, USA), 10 nM 1,25-dihydroxyvitamin D3 (Sigma-Aldrich, St. Louis, MO, USA) and $50 \mu \mathrm{g} / 1$ ascorbic acid-2-phosphate (Wako, Tokyo, Japan). The culture medium was replaced every 3 days. Following 28 days of induction, osteogenic differentiation was assessed by staining with a fresh 0.1\% Alizarin Red solution (Cat. no. 130-22-3; Santa Cruz Biotechnology, Inc.) for $30 \mathrm{~min}$ at $37^{\circ} \mathrm{C}$.

Adipogenic differentiation. The SFMSCs were seeded in 12-well plates at a density of 5,000 cells $/ \mathrm{cm}^{2}$. Following adherence, the complete culture medium was replaced with adipogenic induction medium consisting of H-DMEM, 10\% FBS (both from Gibco), $200 \mathrm{mM}$ indomethacin (Sigma-Aldrich), $0.5 \mathrm{mM}$ isobutylmethylxanthine, $1 \mathrm{mM}$ dexamethasone and $10 \mathrm{mg} / \mathrm{ml}$ insulin (all from MP Biomedicals, Irvine, CA, USA). 
The medium was replaced every 3 days. After 28 days, cell staining was performed with a fresh $0.3 \%$ Oil Red $\mathrm{O}$ solution (Cat. no. 1320-06-5, Santa Cruz Biotechnology, Inc.) for 3 min.

Chondrogenic differentiation. The SFMSCs were harvested using $0.25 \%$ trypsin and approximately $3 \times 10^{5}$ cells were transferred to a $15 \mathrm{ml}$ centrifuge tube. They were then centrifuged at $450 \mathrm{x} \mathrm{g}$ for $8 \mathrm{~min}$, and $500 \mu \mathrm{l}$ of chondrocyte differentiation induction medium [H-DMEM, 1X ITS-A (both from Gibco), $100 \mathrm{nM}$ dexamethasone (MP Biomedicals), $50 \mathrm{mM}$ ascorbic acid, $40 \mathrm{mg} / \mathrm{ml}$ proline (both from Sigma-Aldrich), and $10 \mathrm{ng} / \mathrm{ml}$ transforming growth factor- $\beta 1$ (PeproTech, Rocky Hill, NJ, USA)] were added. The medium was refreshed every 3 days. Following culture for 28 days, the chondrogenic pellets were fixed with $4 \%$ formalin and paraffin-embedded. Chondrogenic differentiation was assessed by $0.1 \%$ Safranin O staining (Cat. no. S2255; Seebio, Shanghai, China) and immunohistochemical staining for collagen II [rabbit anti-human collagen type II antibodies (Sigma-Aldrich) 1:80]. The control group was then incubated with complete culture medium.

Neurogenic differentiation. The cells were plated in 12-well plates and cultured until they reached $70 \%$ confluence, after which the complete culture medium was replaced with a neuronal induction medium that consisted of Neurobasal-A media containing 1X B-27 Supplement (both from Gibco), $20 \mathrm{ng} / \mathrm{ml}$ recombinant human epidermalgrowth factor (rhEGF), $40 \mathrm{ng} / \mathrm{ml}$ basic fibroblast growth factor (bFGF) (both from PeproTech), $10 \mathrm{ng} / \mathrm{ml}$ brain-derived neurotrophic factor (BDNF; ProSpec, East Brunswick, NJ, USA), 1 mM N6,2'-O-dibutyryladenosine 3':5' cyclic monophosphate (dbCAMP; Sigma-Aldrich), $0.5 \mathrm{mM}$ isobutylmethylxanthine (MP Biomedicals), and $10 \mathrm{ng} / \mathrm{ml}$ fibroblast growth factor (FGF)-8 (PeproTech) for $24 \mathrm{~h}$ to induce differentiation. The control group was incubated in complete culture medium. Neuronal differentiation was assessed by immunofluorescence staining for glial fibrillary acidic protein (GFAP; mouse anti-human antibody to GFAP, 1:200; Cat. no. MAB360; Millipore, Billerica, MA, USA).

$R T-q P C R$. Total RNA from the chondrogenic differentiation pellets and other cell samples was extracted using RNeasy mini kit reagents (Qiagen, Valencia, CA, USA) and TRIzol reagent (Roche, Indianapolis, IN, USA), respectively. cDNA was synthesized using the Transcriptor First Strand cDNA Synthesis kit (Roche). The relative expression levels of Runtrelated transcription factor $2(R U N X-2)$, osteocalcin $(O C N)$, peroxisome proliferator activated receptor gamma 2 (PPARG2), lipoprotein lipase ( $L P L)$, SRY-box 9 (SOX9) and MMP13 were quantified using a SYBR-Green qPCR kit (Roche). The primer nucleotide sequences are listed in Table I. The $2^{-\Delta \Delta \mathrm{Ct}}$ method was used to analyze the relative gene expression levels by normalizing against the levels of glyceraldehyde 3-phosphate dehydrogenase (GAPDH) as an endogenous control and calibrating for amplification efficiency. $\Delta \Delta \mathrm{Ct}$ was calculated using the following formula: $\left(\mathrm{Ct}_{\text {target gene }}-\mathrm{Ct}_{\text {gapdh }}\right)$ sample - $\left(\mathrm{Ct}_{\text {target }}\right.$ gene $\left.-\mathrm{Ct}_{\text {gapdh }}\right)$ control.

Detection of actate dehydrogenase ( $L D H)$ cytotoxicity. The humanSFMSCswereseededinto96-wellplatesat10,000cells/well and then treated with $10 \mathrm{ng} / \mathrm{ml} \mathrm{IL-1} \beta, 10 \mathrm{ng} / \mathrm{ml} \mathrm{TNF-} \alpha, 10 \mathrm{ng} / \mathrm{ml}$
Table I. Oligonucleotide primers used in RT-qPCR.

\begin{tabular}{llc}
\hline Gene & \multicolumn{1}{c}{ Primer sequence } & $\begin{array}{r}\text { Product } \\
\text { size (bp) }\end{array}$ \\
\hline GAPDH & $\begin{array}{l}\text { F: GACAGTCAGCCGCATCTTCT } \\
\text { R: TTAAAAGCAGCCCTGGTGAC }\end{array}$ & 178 \\
RUNX2 & F: TCAACGATCTGAGATTTGTGGG & \\
& R: GGGGAGGATTGGGAAGACGG & 81 \\
OCN & F: CCACCGAGACACCATGAGAG & \\
& R: TCAGCCAACTCGTCACAGTC & 267 \\
PPARG2 & F: GCAAACCCCTATTCCATGCTG & \\
& R: CACGGAGCTGATCCCAAAGT & 167 \\
LPL & F: CAAGAGTGAGTGAACAAC & \\
& R: AATTATGCTGAAGGACAAC & 189 \\
SOX9 & F: ACACACAGCTCACTCGACCTTG & \\
& R: AGGGAATTCTGGTTGGTCCTCT & 104 \\
MMP13 & F: GACTGGTAATGGCATCAAGGGA & \\
& R: CACCGGCAAAAGCCACTTTA & 149 \\
& &
\end{tabular}

F, forward; R, reverse.

IL-8/IL-1 $\beta /$ IL-6/IL-10/TNF- $\alpha /$ IL-12p compound, or $10 \mu \mathrm{M}$ NF- $\kappa$ B inhibitor (BAY11-7082; Cat. no. 19542-67-7; Santa Cruz Biotechnology, Inc.) for $12 \mathrm{~h}$. We then measured the activity of $\mathrm{LDH}$ released from the cells using the cytotoxicity detection kit (LDH; Roche) following the manufacturer's instructions.

Detection of cytokines secreted by SFMSCs. We measured the concentrations of IL-8, IL- $1 \beta$, IL- 6 , IL-10, TNF- $\alpha$ and IL-12p in the culture medium of SFMSCs following treatment with cytokines in vitro using a BD CBA Human Soluble Protein Master Buffer kit (Human Inflammatory Cytokine kit; Cat. no. 551811; BD Biosciences).

Immunofluorescence staining for $N F-\kappa B$. The human SFMSCs were plated in 24-well plates and allowed to grow onto coverslips placed in each well. At approximately 50\% confluence, the wells received either the same volume of diluting agent as the control group or $10 \mathrm{ng} / \mathrm{ml} \mathrm{IL-1} \beta$ for $2 \mathrm{~h}$. The medium was then aspirated, and the cells were washed twice with phosphate-buffered saline (PBS). The cells were then fixed in $4 \%$ paraformaldehyde for $30 \mathrm{~min}$ prior to treatment with $3 \%$ Triton $\mathrm{X}-100$ for $15 \mathrm{~min}$ at approximately $26^{\circ} \mathrm{C}$. The cells were blocked for $2 \mathrm{~h}$ with $5 \%$ bovine serum albumin. After washing with PBS, the cells were stained with rabbit anti-human NF-кB p65 antibody (1:400; Cell Signaling Technology, Boston, MA, USA) for $18 \mathrm{~h}$ at $4^{\circ} \mathrm{C}$. After washing with $1 \mathrm{X}$ PBS, the cells were incubated with the secondary antibody, DyLight 549 goat anti-rabbit IgG antibody (1:100; Cat. no. E032320-01; EarthOx LLC, San Francisco, CA, USA) for $60 \mathrm{~min}$ at $37^{\circ} \mathrm{C}$. After washing with PBS, the cells were incubated with 4',6-diamidino-2-phenylindole (DAPI; Cell Signaling Technology) for $5 \mathrm{~min}$. The cells were viewed under a fluorescent microscope (Olympus, Tokyo, Japan). As a specificity control, the cells were treated using the same process, but without incubation with a primary antibody. 
Dual-luciferase reporter assay. The human SFMSCs were seeded into 96-well plates at 5,000 cells/well. pGL3-basicNF-kB-REVector and pRL-SV40-Renilla were transfected into the SFMSCs using ViaFect transfection reagent (both from Promega, Madison, WI, USA) according to the manufacturer's instructions. Following incubation for $48 \mathrm{~h}$, cells were treated with the same volume of diluting agent as the control group or $10 \mathrm{ng} / \mathrm{ml} \mathrm{IL-1 \beta}$ for $2 \mathrm{~h}$. Luciferase activity in the SFMSCs was detected using the GloMax-MultiDetection system and the Dual-Luciferase Reporter assay kit (Cat. no. E4030) (both from Promega).

CBA assay. The human SFMSCs were seeded into $10-\mathrm{mm}$ plates and cultured until they reached $80 \%$ confluence. The cells were treated with cytokines and/or inhibitors. Inhibitors [BAY117082 (Cat. no. 19542-67-7; Santa Cruz Biotechnology, Inc.), anti-TNF- $\alpha$ (167348; Ebioscience, San Diego, CA ,USA)] were added $1 \mathrm{~h}$ prior to cytokine treatment. The empty plate using the same culture medium, but without cells as the negative control. IL-6 and IL-8 expression in the culture medium was determined using a CBA kit (Human Inflammatory Cytokine kit; Cat. no. 551811; BD Biosciences). Double-stranded DNA was detected using Quant-iT PicoGreen dsDNA reagent (Invitrogen, Carlsbad, CA, USA) as an endogenous control.

Western blot analysis. Cellular proteins were extracted using RIPA buffer (Cell Signaling Technology) and separated by sodium dodecyl sulfate-polyacrylamide gel electrophoresis (SDS-PAGE). The tissue samples were electrophoresed in a stacking gel $(5 \% \mathrm{w} / \mathrm{v})$ for $30 \mathrm{~min}$ and run on a running gel $(10 \% \mathrm{w} / \mathrm{v})$ for $120 \mathrm{~min}$. Proteins were transferred electrophoretically onto PVDF membranes by applying $200 \mathrm{~mA}$ for $75 \mathrm{~min}$. The membranes were first reacted with antibodies against NF-кB p65 (1:1,000; Cat. no. 3033; Cell Signaling Technology) and GAPDH (1:2,000; Cat. no. Mab5465; MultiSciences Biotech Co., Hangzhou, China) overnight at $4^{\circ} \mathrm{C}$, and then with $\mathrm{IgG}$ conjugated to horseradish peroxidase (Cat. no. 7076; Cell Signaling Technology) for $1 \mathrm{~h}$ at room temperature. The target bands were visualized by an enhanced chemiluminescence method. The corrected optical density of the protein bands was quantified using a Bio-Rad image analyzer (Bio-Rad, Hercules, CA, USA).

Effect of IL-1 $\beta$ on the chondrogenic differentiation of SFMSCs. The chondrogenic differentiation procedure was performed as described above, with the addition of the corresponding cytokines. In order to evaluate the chondrogenic differentiation potential upon stimulation with rhIL-1 $\beta$, rhIL- 6 or rhIL-8 (PeproTech), we measured the production of sulfated glycosaminoglycans (sGAG) in the chondrogenic pellets stimulated with rhIL-6 or rhIL-8, and the mRNA expression of SOX 9 and MMP13 in the chondrogenic pellets, mediated by rhIL-1 $\beta$.

$s G A G$ assay. The samples were digested overnight at $56^{\circ} \mathrm{C}$ using $100 \mu \mathrm{l}$ of a $50 \mu \mathrm{g} / \mathrm{ml}$ proteinase $\mathrm{K}$ solution in $100 \mathrm{mM}$ $\mathrm{Na}_{2} \mathrm{HPO}_{4}$ ( $\mathrm{pH}$ 8.0). Proteinase $\mathrm{K}$ was then inactivated by heating the preparation for $10 \mathrm{~min}$ at $90^{\circ} \mathrm{C}$. Following centrifugation, $500 \mu \mathrm{l}$ of working DMMB solution were added to $50 \mu \mathrm{l}$ of proteinase K-treated or untreated sample, and the mixture was vigorously vortexed for $30 \mathrm{~min}$ to promote complete
GAG/DMMB complexation. The samples were then centrifuged at $12,000 \mathrm{x}$ g for $10 \mathrm{~min}$. The supernatant was discarded, and the pellet was dissolved with DMMB decomplexation solution and vortexed for $30 \mathrm{~min}$. The absorbance at $656 \mathrm{~nm}$ was used to quantify the sGAG levels.

Statistical analysis. In this study, the numerical data are expressed as the means \pm standard deviation (SD). Statistical significance was evaluated using the Student's t-test, and a value of $\mathrm{p}<0.05$ was considered to indicate a statistically significant difference.

\section{Results}

Cytokine expression in the synovial fluid of patients with $T M D$. In the present study, we randomly selected 19 patients with TMD (19 laterals) to evaluate the IL-8, IL-1 $\beta$, IL-6, IL-10, TNF- $\alpha$ and IL-12p expression levels in the synovial fluid of the TMJ. The levels of these cytokines were 18.23$282.24 \mathrm{pg} / \mathrm{ml}$ (average $88.25 \mathrm{pg} / \mathrm{ml}$ ), $0.57-424.01 \mathrm{pg} / \mathrm{ml}$ (average $120.21 \mathrm{pg} / \mathrm{ml}$ ), 2.80-498.44 pg/ml (average $120.73 \mathrm{pg} / \mathrm{ml}$ ), 7.63$215.54 \mathrm{pg} / \mathrm{ml}$ (average $58.61 \mathrm{pg} / \mathrm{ml}$ ), $0.00-321.55 \mathrm{pg} / \mathrm{ml}$ (average $85.48 \mathrm{pg} / \mathrm{ml}$ ), and $36.39-482.77 \mathrm{pg} / \mathrm{ml}$ (average $157.32 \mathrm{pg} / \mathrm{ml}$ ), respectively. The DI of these patients with TMD ranged from 0.05 to 0.57 (average 0.27 ). A more detailed summary of the cytokine expression profiles in the synovial fluid of the patients with TMD is depicted in Fig. 1.

Characteristics of SFMSCs in vitro. After the synovial fluid samples were plated and cultured for approximately 2 weeks, cell clones were observed in culture (Fig. 2A), and the cells exhibited a typical fibroblastic spindle shape (Fig. 2B). The SFMSCs expressed CD90, CD105, CD73 and CD44, whereas CD45, CD34, CD11b, CD19 and HLA-DR were not detected by FACS analysis (Fig. 3).

Differentiation of SFMSCs. Following culture in osteogenic induction medium for 4 weeks, calcium deposits were observed in the SFMSCs (Fig. 4B), while none were observed in the control group (Fig. 4A), as shown by by Alizarin Red staining (Fig. 4A and $\mathrm{B})$. The expression of the osteogenic transcription factor, $R U N X 2$, was also found to be higher in the group subjected to osteogenic differentiation (induced group) compared to the controls (Fig. 4C). The expression of $O C N$, which is a marker for late-stage-matrix-producing osteoblasts, was significantly increased (Fig. 4D).

Following 28 days of culture in adipogenic induction medium, the SFMSCs had developed into lipid-laden fat cells that stained Oil Red O-positive (Fig. 4F), while this was not observed in the control group (Fig. 4E). In addition, PPARG2 expression was significantly increased (Fig. 4G). The gene encoding $L P L$, a lipid exchange enzyme that is upregulated during adipogenesis, was significantly upregulated at day 28 of induction (Fig. 4H).

Following 28 days of culturein chondrogenic inductionmedium, the formation of cartilage pellets was evident (Fig. 4I), and this was not observed in the controls. The histological sections of the cartilage pellets were positively stained with Safranin O (Fig. 4J), as also shown in our previous study (6). In addition, there was extensive immunoreactivity for collagen type II, a characteristic 

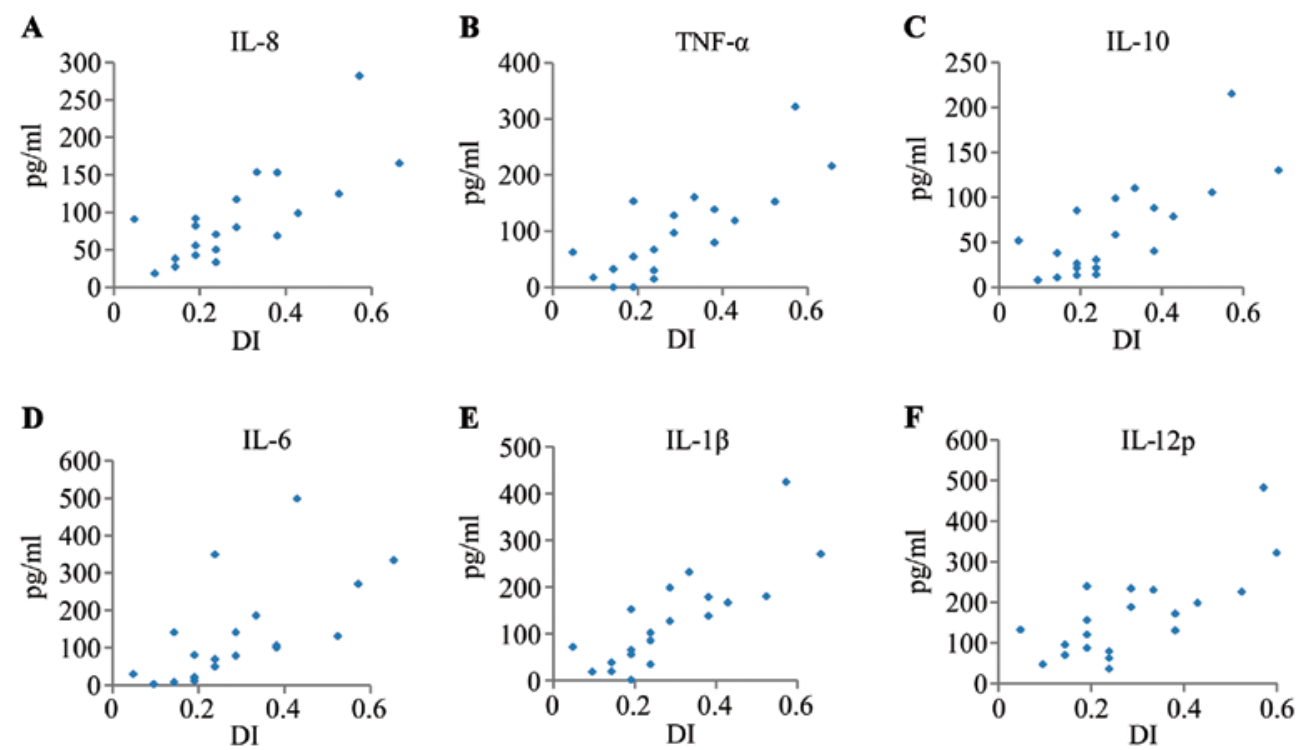

Figure 1. (A-F) Cytokine expression profiles of synovial fluid from patients with temporomandibular joint disorders (TMD). Subjects were evaluated using the dysfunction index (DI) described in the study by Fricton JR and Schiffman (23) .
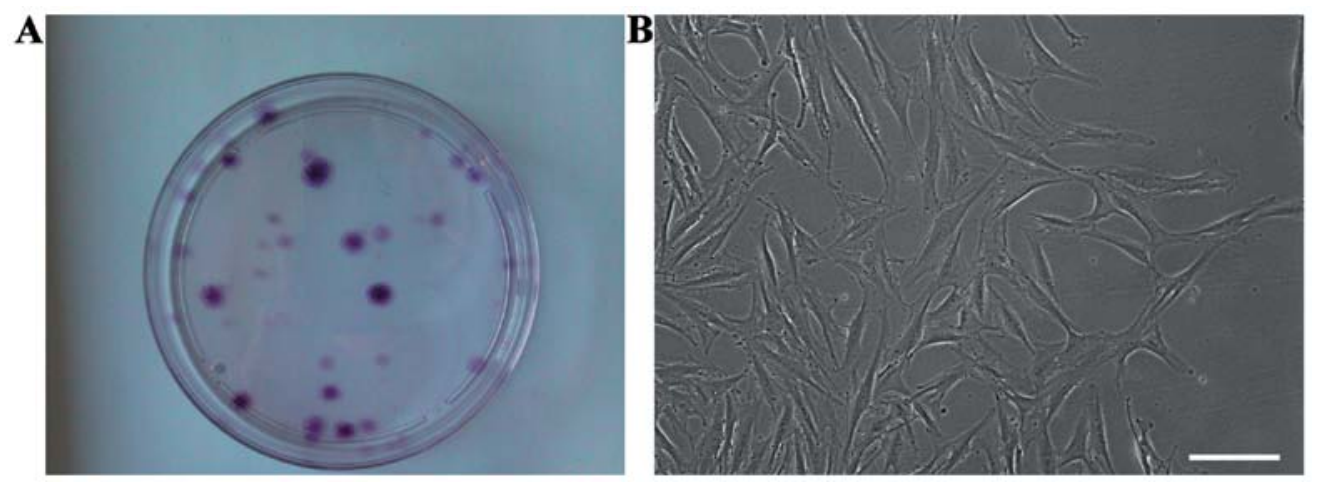

Figure 2. Characteristics of synovial fluid-derived mesenchymal stem cells (SFMSCs) in vitro. (A) Clones of SFMSCs were observed after in vitro culture of synovial fluid samples for 2 weeks. (B) Shape of SFMSCs in monolayer culture. Scale bars, $100 \mu \mathrm{m}$.

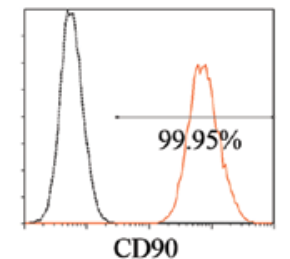

CD90

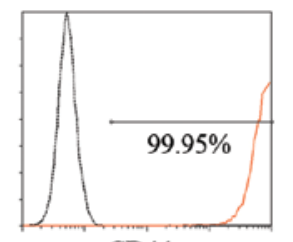

CD44

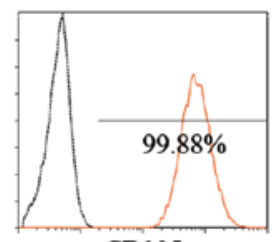

CD105

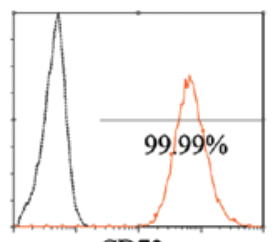

CD73

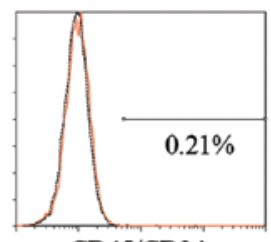

CD45/CD34

$\mathrm{CD} 11 \mathrm{~b} / \mathrm{CD} 19 / \mathrm{HLA}-\mathrm{DR}$

Figure 3. Mesenchymal stem cell (MSC) surface marker assay in synovial fluid-derived mesenchymal stem cells (SFMSCs).

collagen found in cartilage (Fig. 4K), whereas no immunostaining was detected in the respective controls (Fig. 4L).

Following $24 \mathrm{~h}$ of culture in neurogenic induction medium, the cells exhibited a bipolar and stellate morphology (Fig. 4N), while the cells in the control group exhibited a typical fibroblastic spindle shape (Fig. 4M). The expression of the glia-associated marker, glial fibrillary acidic protein (GFAP, a specific marker for the astrocyte lineage) in SFMSCs was demonstrated by immunofluorescence staining (Fig. 4O). No immunostaining was detected in the respective control cells (Fig. 4P).

Cytotoxicity detection. None of the treatments induced a significant increase in LDH activity compared to the controls, indicating that they did not exert cytotoxic effects on the SFMSCs (data not shown).

Cytokine secretion from SFMSCs stimulated with the inflammatory cytokines, $I L-8, I L-1 \beta, I L-6, I L-10, T N F-\alpha$ and $I L-12 p$. We then determined which cytokines were secreted by SFMSCs upon exposure to the inflammatory cytokines, IL-8, IL-1 $\beta$, IL-6, IL-10, TNF- $\alpha$ and IL-12p. We found that only the IL-8 and IL-6 levels increased significantly following stimulation with IL-1 $\beta$, independent of IL-8/IL-1 $\beta / \mathrm{IL}-6 / \mathrm{IL}-10 / \mathrm{TNF}-\alpha / \mathrm{IL}-12 p$ compound stimulation (Fig. 5E and F). This secretion profile was also observed following stimulation with, or the blockade of, TNF- $\alpha$ signaling (Fig. 6). IL-8 and IL-6 expres- 

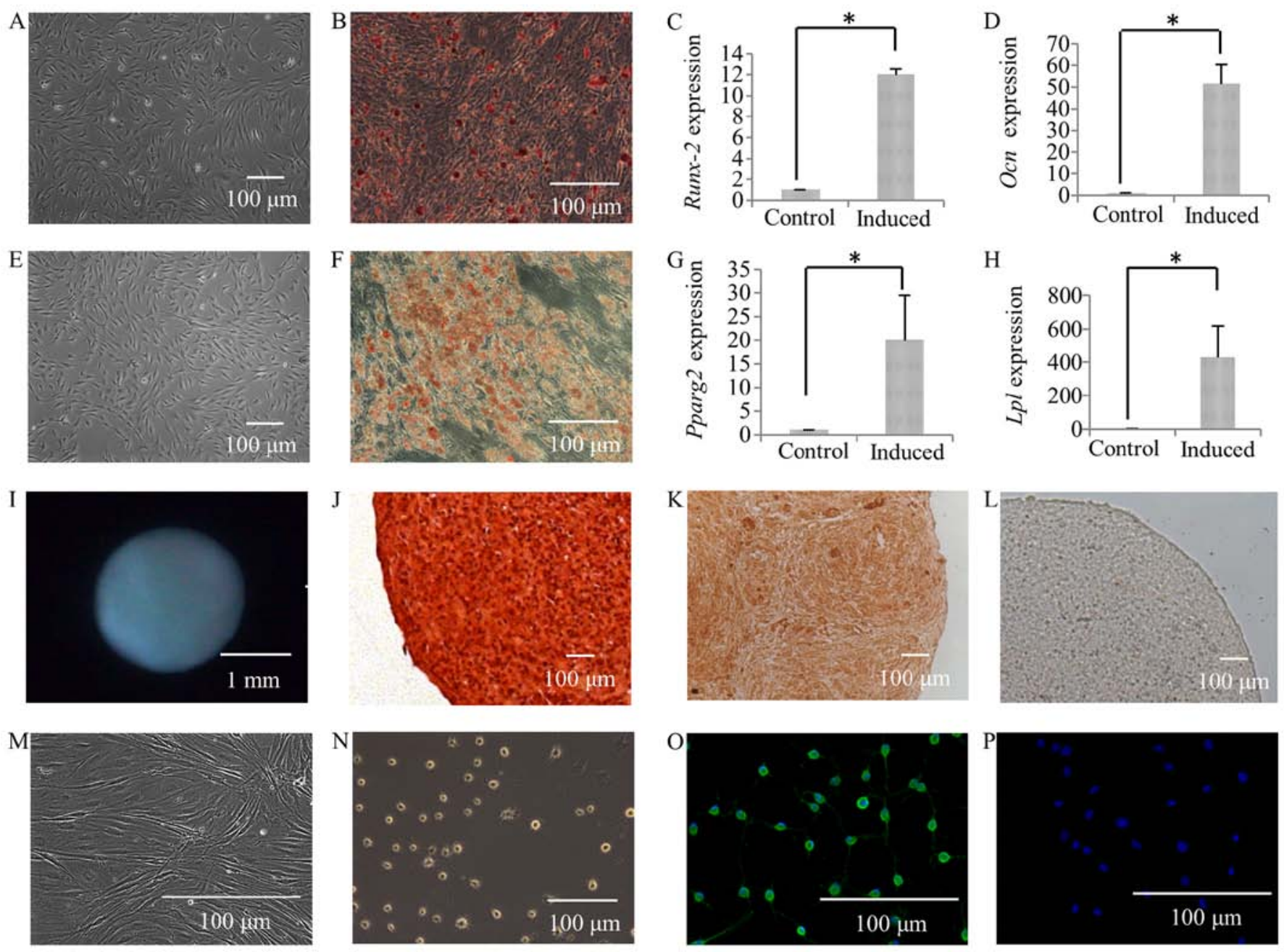

Figure 4. Alizarin Red staining of SFMSCs prior to culture in osteogenic induction medium (A), and following culture in osteogenic induction medium for 4 weeks (B), and the expression of RUNX2 (C) and $O C N(\mathrm{D})$ was compared between the osteogenic induction group and the control group. Oil Red $\mathrm{O}$ staining of SFMSCs prior to culture in adipogenic induction medium (E) and following culture in adipogenic induction medium for 4 weeks (F), and the expression of PPARG2 (G) and $L P L(\mathrm{H})$ in the adipogenic induction group was compared to that in controls. Following culture in chondrogenic induction medium for 4 weeks, cartilage pellets formed in the tube (I), and the pellets were subjected to Safranin O staining (J) and immunohistochemical staining for type II collagen (K). The control group sections, which were treated using the same immunohistochemical staining process but without incubation with type II collagen antibody, exhibited negative staining (L). The morphology of SFMSCs prior to culture in neurogenic induction medium (M) and following culturing in neurogenic induction medium for $24 \mathrm{~h}(\mathrm{~N})$; Cells after induction $(\mathrm{O})$ were also stained for GFAP, while the control group $(\mathrm{P})$ was not. Significant differences between the 2 groups are indicated by single asterisks ( $\mathrm{p}<0.05)$.

sion was markedly dependent on the concentration of IL-1 $\beta$ used (Fig. 5A-E).

To determine whether NF- $\mathrm{KB}$ was responsible for the effects of IL-1 $\beta$, we performed immunofluorescence staining using an antibody to the NF- $\kappa \mathrm{B}$ p65 subunit (Fig. 7A and B). Compared to the control group, the nuclei of the SFMSCs stimulated with IL-1 $\beta$ were strongly stained, indicating the induction of NF- $\mathrm{KB}$ activity. The results of western blot analysis revealed that NF-kB p65 expression increased in response to IL-1 $\beta$ (Fig. 7D). The increased NF- $\kappa \mathrm{B}$ activity was also confirmed by dualluciferase reporter assays (Fig. 7C). Compared with the untreated control group, the levels of IL-8 and IL-6 were much higher in the SFMSCs stimulated with $10 \mathrm{ng} / \mathrm{ml} \mathrm{IL}-1 \beta$ for $2 \mathrm{~h}$ (Fig. 8A-C). Pre-treatment with NF- $\kappa B$ inhibitor for $1 \mathrm{~h}$ significantly attenuated the IL-1 $\beta$-dependent induction of IL- 8 and IL-6 expression (Fig. 8C and D). Taken together, these data indicate that the secretion of IL- 6 and IL- 8 by SFMSCs upon stimulation with IL- $1 \beta$ in vitro requires the activation of the NF- $\mathrm{kB}$ pathway.
Influence of cytokines on the chondrogenesis of SFMSCs in vitro. Compared to the untreated cells, the induction of chondrogenic differentiation in the cells stimulated with IL-1 $\beta$ was associated with the downregulation of $\operatorname{SOX} 9$ and the upregulation of MMP13 (Fig. 9).

To determine the relative contributions of IL- 6 and IL- 8 to the inhibition of chondrogenesis, we exposed the SFMSCs to IL-6 and IL-8 and quantitatively analyzed the sGAG content. The sGAG levels of the cartilage pellets exposed to $0,0.1,1$ and $10 \mathrm{ng} / \mathrm{ml} \mathrm{IL-6} \mathrm{decreased} \mathrm{from} 13.17 \pm 0.48$ to $9.20 \pm 0.39 \mu \mathrm{g} /$ pellet (300,000 cells/pellet) (Fig. 10A). By contrast, there were no significant changes observed in SGAG synthesis following exposure to IL-8 (Fig. 10B).

\section{Discussion}

MSCs are adult stem cells with notable self-renewal and multilineage differentiation capacities (24). MSC-based technology 


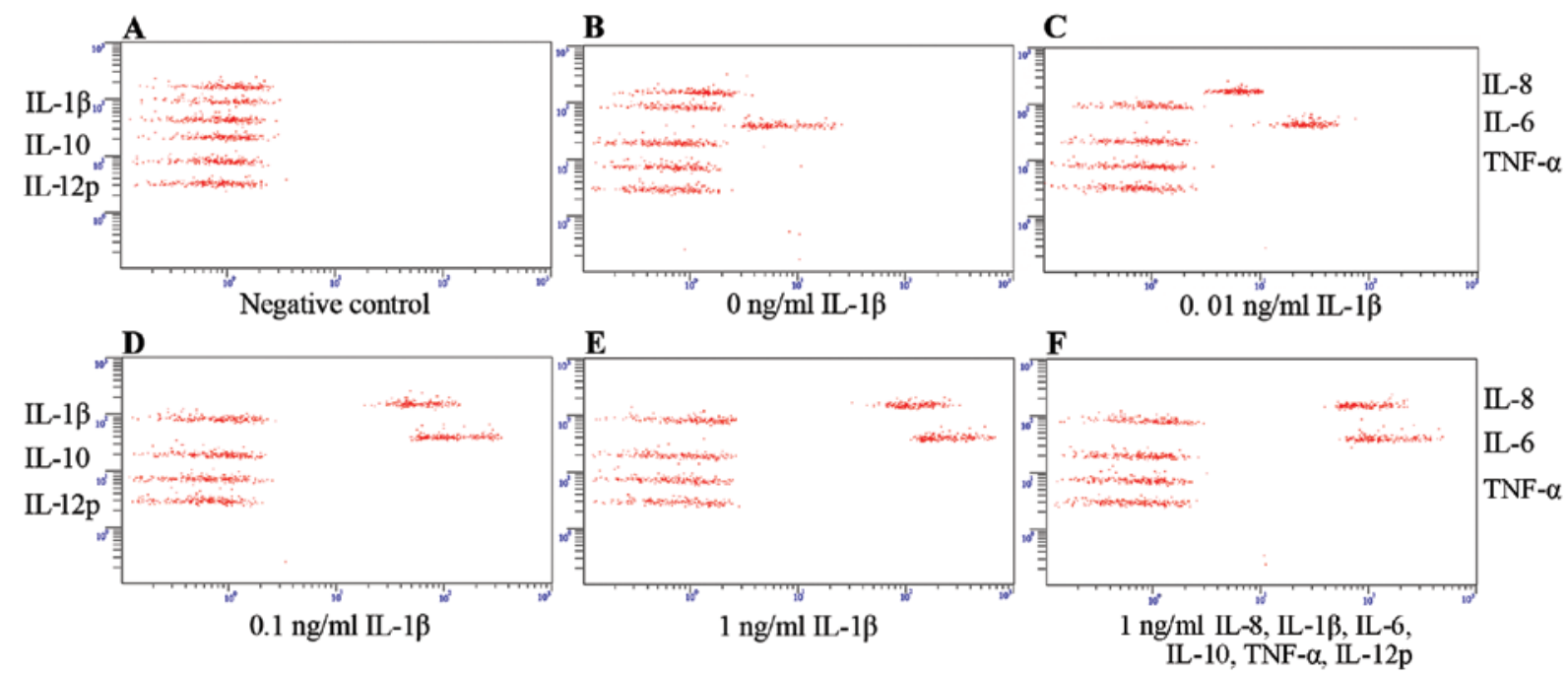

Figure 5. Secreted cytokine profiles of synovial fluid-derived mesenchymal stem cells (SFMSCs). (A) In culture medium without cells, (B) without interleukin (IL)- $1 \beta$ stimulation, (C-E) following stimulation with IL-1 $\beta$ at the indicated doses, and (F) with $1 \mathrm{ng} / \mathrm{ml} \mathrm{IL-8/IL-1 \beta /IL-6/IL-10/tumor} \mathrm{necrosis}$ factor (TNF)- $\alpha / \mathrm{IL}-12 \mathrm{p}$ for $12 \mathrm{~h}$.
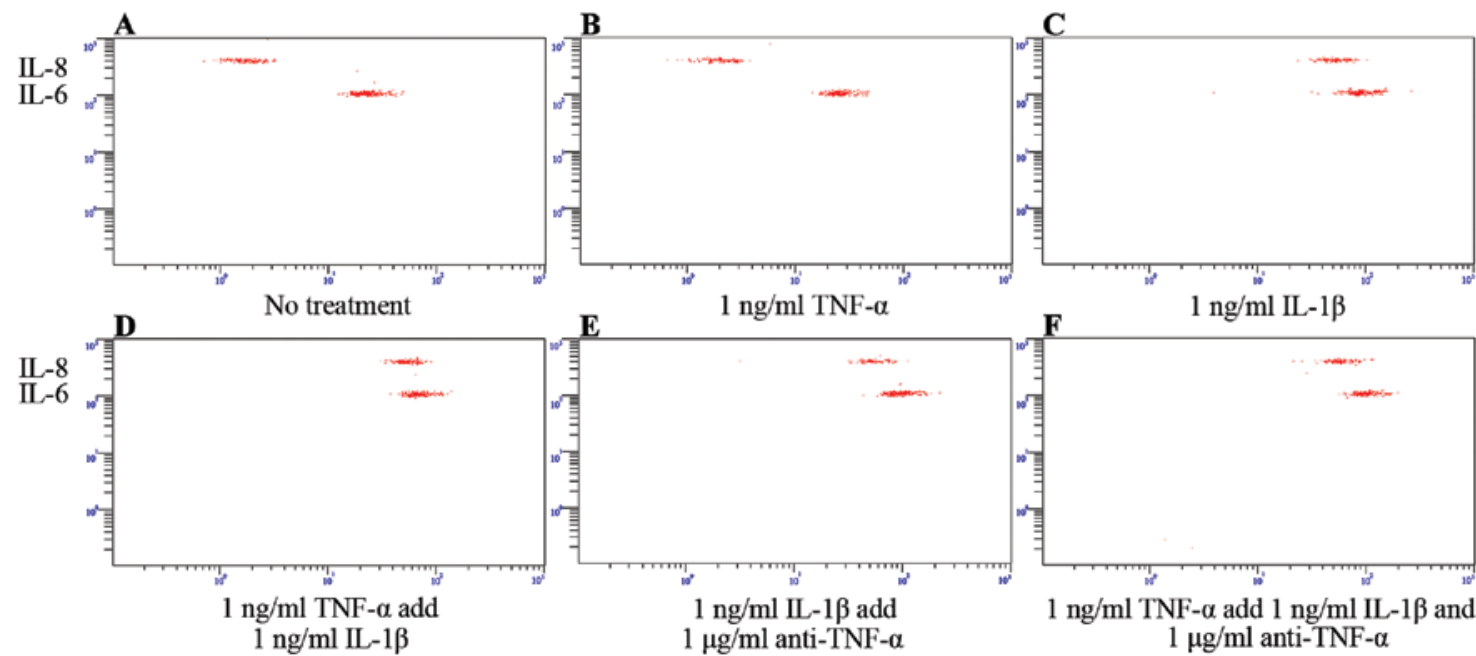

Figure 6. Tumor necrosis factor- $\alpha$ (TNF- $\alpha$ )- and interleukin (IL)-1 $\beta$-dependent cytokine secretion from synovial fluid-derived mesenchymal stem cells (SFMSCs).

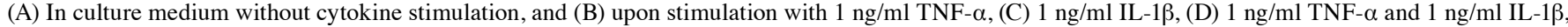

(E) $1 \mathrm{ng} / \mathrm{ml} \mathrm{IL-}-1 \beta$ and $1 \mu \mathrm{g} / \mathrm{mL}$ anti-TNF- $\alpha$, and (F) $1 \mathrm{ng} / \mathrm{ml} \mathrm{TNF-} \alpha$ and $1 \mathrm{ng} / \mathrm{ml} \mathrm{IL-1} \beta$ with the addition of $1 \mu \mathrm{g} / \mathrm{ml}$ anti-TNF- $\alpha$ for $12 \mathrm{~h}$.
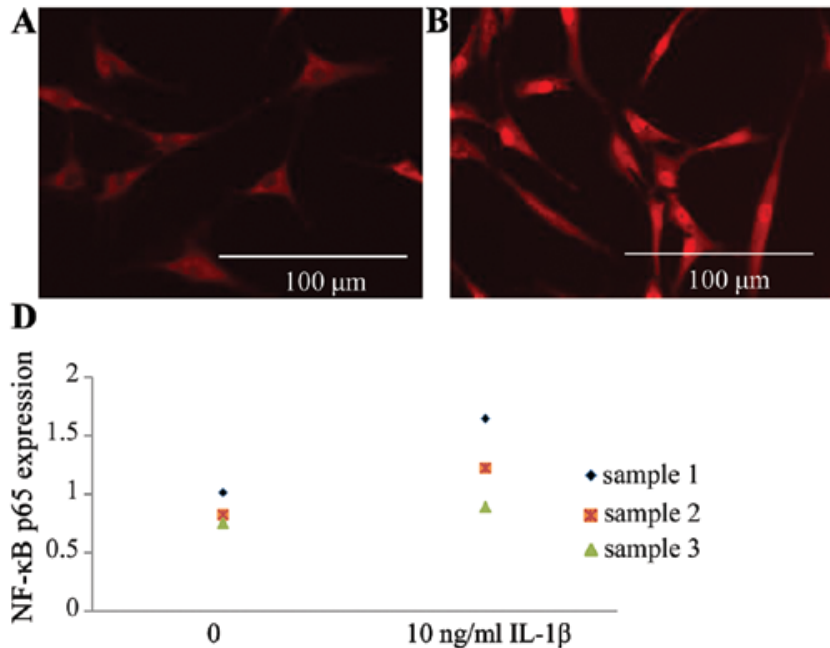

- sample 1

«sample 2

$\triangle$ sample 3
C

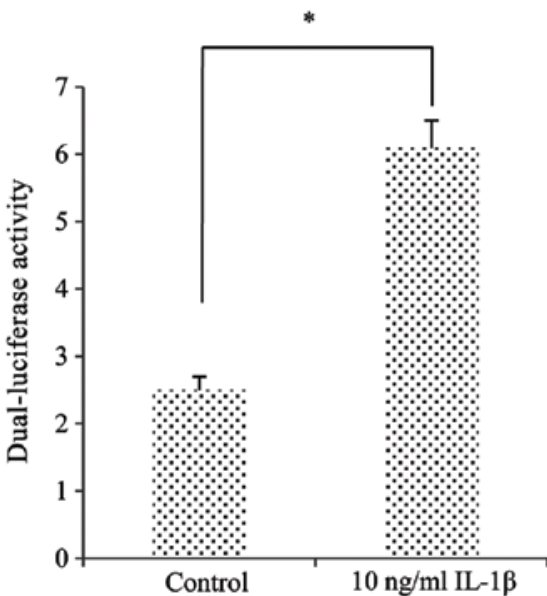

Figure 7. Interleukin-1 $\beta$ (IL-1 $\beta$ )-dependent activation of the nuclear factor- $\kappa B$ (NF- $\kappa B$ ) pathway in synovial fluid-derived mesenchymal stem cells (SFMSCs).

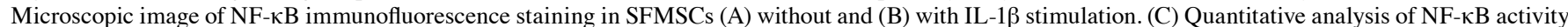
in response to IL-1 $\beta$ as determined by a dual-luciferase assay. (D) Western blot analysis of phospho-NF- $\mathrm{kB}$ in IL-1 $\beta$-treated and control groups. Significant differences between the 2 groups are indicated by a single asterisk ( $(\mathrm{p}<0.05)$. 


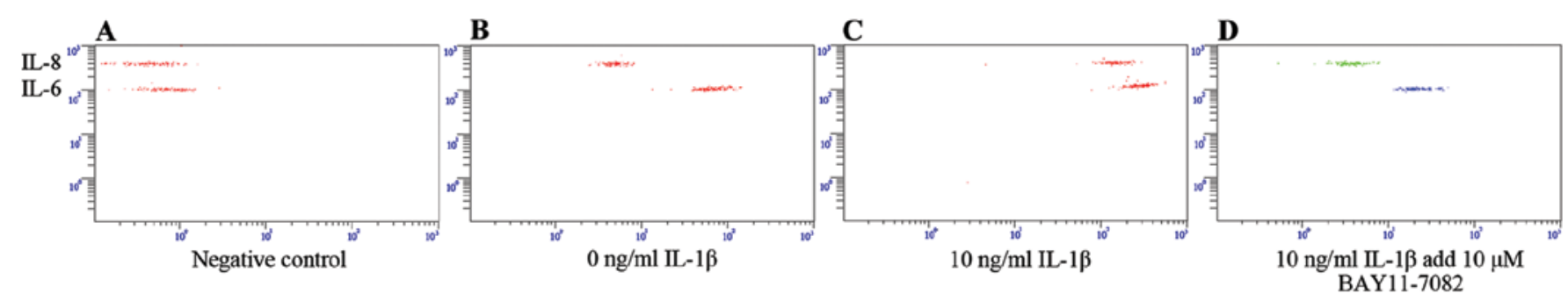

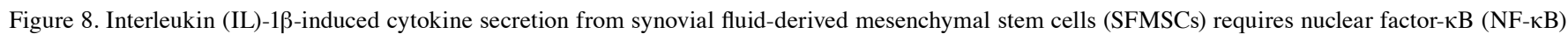

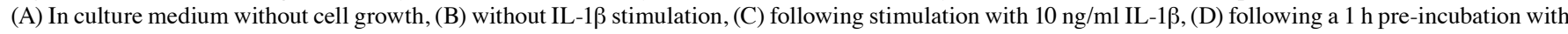
$10 \mu \mathrm{M}$ BAY11-7082 (NF- $\mathrm{KB}$ inhibitor) prior to the addition of $10 \mathrm{ng} / \mathrm{ml} \mathrm{IL}-1 \beta$.
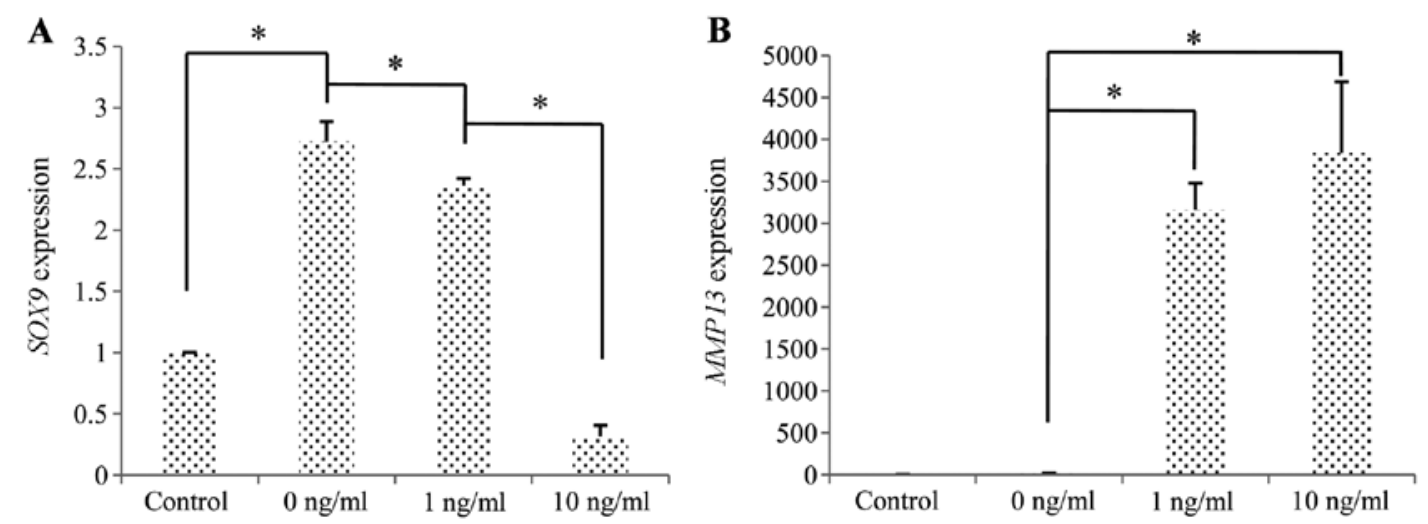

Figure 9. Influence of interleukin (IL)-1 $\beta$ on chondrogenesis of synovial fluid-derived mesenchymal stem cells (SFMSCs) in vitro. RT-qPCR of chondrogenic markers. Statistically significant suppression of (A) SOX9 and the upregulation of (B) MMP13 are shown. Significant differences between the 2 groups are indicated by a single asterisk $(* \mathrm{p}<0.05)$.

A

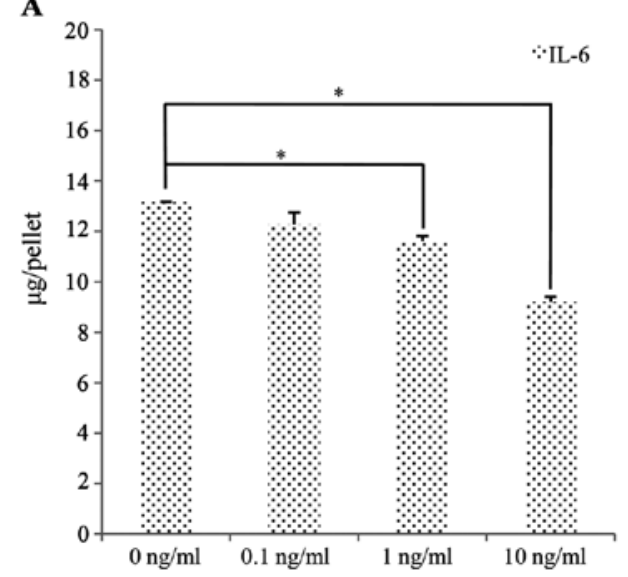

B

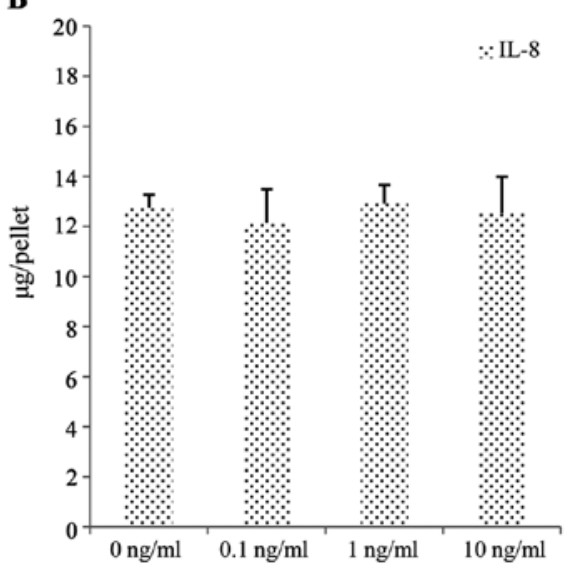

Figure 10. Effect of interleukin (IL)-6 and IL-8 on the levels of sulfated glycosaminoglycans (sGAG), a marker of chondrogenesis. The levels of sGAG was significantly decreased in (A) IL-6-treated chondrogenesis pellets in a concentration-dependent manner. The levels of sGAG were not significantly decreased in (B) the IL-8-treated chondrogenic pellets. Significant differences between the 2 groups are indicated by a single asterisk ( $\left.{ }^{*}<<0.05\right)$.

is considered one of the most promising cell-based treatment options for several diseases, including those associated with tissue injury (25). Various stem cell sources have been investigated for the repair of damaged tissue. Synovium-derived MSCs exist in the same microenvironment as articular cartilage and display the optimal potential for both proliferation and chondrogenesis when compared with other MSC sources (26-28).

In this study, cells isolated from synovial fluid samples exhibited a fibroblastic spindle-like shape and expressed CD90, CD105, CD73 and CD44; they did not express CD45,
CD34, CD11b, CD19 or HLA-DR. These cells also exhibited multilineage potential and thus match the criteria for human MSCs proposed by the Mesenchymal and Tissue Stem Cell Committee of the International Society for Cellular Therapy (ISCT) (24). SFMSCs are a promising cellular resource for autologous articular cartilage repair, as they are simple to isolate and culture, and their introduction into the host does not cause much trauma. Although the existence of SFMSCs has been documented in some studies $(2,4,5)$, research into the biological characteristics of SFMSCs in 
TMD is limited. However, particular attention should be paid to the way in which SFMSCs are used in the clinic, as the safety and efficacy of the procedure are paramount.

Pro-inflammatory cytokines are key contributors to TMD pathology. Indeed, cytokine regulatory networks are welldocumented features of arthritis. The concentrations of the pro-inflammatory cytokines, IL-1 $\beta$, IL-6, IL-8, IL-10, IL-12p and TNF- $\alpha$, in patients with TMD are much higher than those in non-affected individuals; this leads to synovitis and the production of MMPs. The effects of individual cytokines are target-tissue-dependent. Fibroblast-like synoviocytes in the joint are considered major effectors of cartilage destruction, and they perpetuate inflammation by producing cytokines and degradative enzymes (29). In this study, we simulated a proinflammatory environment by treating SFMSCs with IL-1 $\beta$, IL-6, IL-8, IL-10, IL-12p and TNF- $\alpha$ in vitro.

We observed a robust secretion of IL- 6 and IL- 8 by SFMSCs following stimulation with IL-1 $\beta$ in a concentration-dependent manner, and this was independent of IL-8, IL-6, IL-10, TNF- $\alpha$ and IL-12p stimulation. IL-8 is one of the most potent chemoattractants for neutrophils and T lymphocytes (30). IL-6 is important not only in the orchestration of the overall cytokine network, but also as it plays a direct role in destruction of the joint (30). Therefore, SFMSCs appear to be an alternative source of inflammatory cytokines.

Pro-inflammatory cytokines in the inflammatory milieu can modulate some of the fundamental characteristics of MSCs (31-33). There are studies on the beneficial effects of BMSCs on cartilage function in OA $(34,35)$. However, Djouad et al observed a switch in the behavior of MSCs depending on the inflammatory environment. Specifically, the injection of MSCs into the inflamed tissue in a collagen-induced arthritis model had no beneficial effects on arthritis severity, and in some cases it even aggravated the collagen-induced arthritis symptoms (36). Augello et al (34) attributed these effects to the allogeneic C3H10T1/2 cells used by Djouad et al, as it is an immortalized cell line that may have lost the expression of immunosuppressors. Liu and Hwang reported that the continuous exposure of MSCs from cord blood to IL-1 $\beta$ facilitated adipogenic maturation (37). However, whether or not SFMSCs in the TMD microenvironment have beneficial effects on cartilage repair remains unclear.

We further evaluated the chondrogenic differentiation potential of SFMSCs following stimulation with IL-1 $\beta$, a critical cytokine that mediates the activation of inflammatory and degradative pathways that are associated with TMD. We found that the expression of $S O X 9$, which is a chondrogenic marker, was significantly decreased following exposure to IL-1 $\beta$. By contrast, we observed an increased expression of the gene encoding $M M P 13$, the major protease involved in degradation of the cartilage extracellular matrix, and a factor in OA progression. These results indicate that IL-1 $\beta$ impedes the chondrogenic differentiation of SFMSCs in the human TMJ. However, further studies are required to elucidate the molecular mechanisms that underlie this process.

Djouad et al reported that MSC-like cells from the synovial membrane expressed higher levels of transcripts for macrophage inflammatory protein (MIP2)- $\alpha$, IL-6 and IL-8 (38). IL-6 and IL-8, which are produced mainly in response to IL-1 $\beta$, are significant contributors to TMJ disorders, such as synovitis, arthralgia and OA $(30,39,40)$. We further demonstrated that IL-6 significantly inhibited the SFMSC-dependent sGAG production that accompanies the induction of chondrogenesis. By contrast, IL-8 did not have this effect, indicating that IL-6 is a key mediator of the IL-1 $\beta$-dependent inhibition of chondrogenic differentiation.

The NF- $\mathrm{BB}$ pathway plays a major role in transducing inflammatory and catabolic signals in joint degeneration (41).In this study, to further determine whether NF- $\mathrm{KB}$ plays a pivotal role in IL-1 $\beta$-mediated IL- 6 upregulation, we first examined the association between NF- $\mathrm{KB}$ activity and the presence of IL-6 and IL-8. We found that NF- $\kappa$ B activity in the SFMSCs increased significantly upon exposure to IL-1 1 . Furthermore, the IL-1 $\beta$-dependent expression of IL- 6 and IL- 8 was reduced to the basal levels when the cells were pre-treated with an NF- $\kappa \mathrm{B}$ inhibitor, confirming that the NF- $\kappa \mathrm{B}$ pathway indeed contributes to the IL-1 $\beta$-mediated IL- 6 upregulation. Thus, the detailed regulatory mechanisms involved in the NF- $\kappa$ B pathway and the biological effects of SFMSCs in vivo require further investigation.

In conclusion, in this study, we found that IL- $1 \beta$ plays an important role in regulation of the biological behavior of SFMSCs in an inflammatory milieu. In doing so, IL-1 $\beta$ impedes the chondrogenic differentiation of SFMSCs. The upregulation of IL-6 and the activation of the NF- $\mathrm{KB}$ pathway contribute to this biological behavior. Our results indicate the potential adverse effects of IL-1 $\beta$ on the chondrogenic differentiation of SFMSCs, which may provide new insight into the pathogenesis of TMD. Our findings also provide an experimental basis for the existence of MSCs that initiate self-renewal in the synovial fluid.

\section{Acknowledgements}

We would like to thank all the nurses and physicians for their valuable assistance in this study. This study was supported by grants from the National Science Foundation of China (81271115), The founders had no role in the study design, data collection and analysis, decision to publish, or preparation of this manuscript.

\section{References}

1. Gauer RL and Semidey MJ: Diagnosis and treatment of temporomandibular disorders. Am Fam Physician 91: 378-386, 2015.

2. Jones EA, English A, Henshaw K, Kinsey SE, Markham AF, Emery $\mathrm{P}$ and McGonagle D: Enumeration and phenotypic characterization of synovial fluid multipotential mesenchymal progenitor cells in inflammatory and degenerative arthritis. Arthritis Rheum 50: 817-827, 2004.

3. Zhang S, Muneta T, Morito T, Mochizuki T and Sekiya I: Autologous synovial fluid enhances migration of mesenchymal stem cells from synovium of osteoarthritis patients in tissue culture system. J Orthop Res 26: 1413-1418, 2008.

4. Harvanová D, Tóthová T, Sarišský M, Amrichová J and Rosocha J: Isolation and characterization of synovial mesenchymal stem cells. Folia Biol (Praha) 57: 119-124, 2011.

5. Koyama N, Okubo Y, Nakao K, Osawa K, Fujimura K and Bessho K: Pluripotency of mesenchymal cells derived from synovial fluid in patients with temporomandibular joint disorder. Life Sci 89: 741-747, 2011.

6. Sun YP,Zheng YH, Liu WJ, Zheng YL and Zhang ZG: Synovium fragment-derived cells exhibit characteristics similar to those of dissociated multipotent cells in synovial fluid of the temporomandibular joint. PLoS One 9: e101896, 2014. 
7. Sullivan C, Murphy JM, Griffin MD, Porter RM, Evans CH, O'Flatharta C, Shaw G and Barry F: Genetic mismatch affects the immunosuppressive properties of mesenchymal stem cells in vitro and their ability to influence the course of collageninduced arthritis. Arthritis Res Ther 14: R167, 2012.

8. Papadopoulou A, Yiangou M, Athanasiou E, Zogas N, Kaloyannidis P, Batsis I, Fassas A, Anagnostopoulos A and Yannaki E: Mesenchymal stem cells are conditionally therapeutic in preclinical models of rheumatoid arthritis. Ann Rheum Dis 71: 1733-1740, 2012.

9. Jones EA, Crawford A, English A, Henshaw K, Mundy J, Corscadden D, Chapman T, Emery P, Hatton P and McGonagle D: Synovial fluid mesenchymal stem cells in health and early osteoarthritis: Detection and functional evaluation at the single-cell level. Arthritis Rheum 58: 1731-1740, 2008.

10. Sekiya I, Ojima M, Suzuki S, Yamaga M, Horie M, Koga H, Tsuji K, Miyaguchi K, Ogishima S, Tanaka H and Muneta T: Human mesenchymal stem cells in synovial fluid increase in the knee with degenerated cartilage and osteoarthritis. J Orthop Res 30: 943-949, 2012.

11. Lee DH, Sonn CH, Han SB, Oh Y, Lee KM and Lee SH: Synovial fluid CD34- $\mathrm{CD} 44^{+} \mathrm{CD} 90^{+}$mesenchymal stem cell levels are associated with the severity of primary knee osteoarthritis. Osteoarthritis Cartilage 20: 106-109, 2012.

12. Neidhart M, Seemayer CA, Hummel KM, Michel BA, Gay RE and Gay S: Functional characterization of adherent synovial fluid cells in rheumatoid arthritis: Destructive potential in vitro and in vivo. Arthritis Rheum 48: 1873-1880, 2003.

13. Heldens GT, Blaney Davidson EN, Vitters EL, Schreurs BW, Piek E, van den Berg WB and van der Kraan PM: Catabolic factors and osteoarthritis-conditioned medium inhibit chondrogenesis of human mesenchymal stem cells. Tissue Eng Part A 18: 45-54, 2012.

14. Boeuf S, Graf F, Fischer J, Moradi B, Little CB and Richter W: Regulation of aggrecanases from the ADAMTS family and aggrecan neoepitope formation during in vitro chondrogenesis of human mesenchymal stem cells. Eur Cell Mater 23: 320-332, 2012.

15. Li J, Long X, Ke J, Meng QG, Lee WC, Doocey JM and Zhu F: Regulation of HAS expression in human synovial lining cells of TMJ by IL-1beta. Arch Oral Biol 53: 60-65, 2008.

16. Alstergren P, Ernberg M, Kvarnström $M$ and Kopp S: Interleukin-1beta in synovial fluid from the arthritic temporomandibular joint and its relation to pain, mobility, and anterior open bite. J Oral Maxillofac Surg 56: 1059-1066, 1998.

17. Kristensen KD, Alstergren P, Stoustrup P, Küseler A, Herlin T and Pedersen TK: Cytokines in healthy temporomandibular joint synovial fluid. J Oral Rehabil 41: 250-256, 2014

18. Marks PH and Donaldson ML: Inflammatory cytokine profiles associated with chondral damage in the anterior cruciate ligament-deficient knee. Arthroscopy 21: 1342-1347, 2005.

19. Kobayashi M, Squires GR, Mousa A, Tanzer M, Zukor DJ, Antoniou J, Feige U and Poole AR: Role of interleukin-1 and tumor necrosis factor alpha in matrix degradation of human osteoarthritic cartilage. Arthritis Rheum 52: 128-135, 2005.

20. Fan Z, Söder S, Oehler S, Fundel K and Aigner T: Activation of interleukin-1 signaling cascades in normal and osteoarthritic articular cartilage. Am J Pathol 171: 938-946, 2007.

21. Goldring MB, Otero M, Plumb DA, Dragomir C, Favero M, El Hachem K, Hashimoto K, Roach HI, Olivotto E, Borzì RM, et al: Roles of inflammatory and anabolic cytokines in cartilage metabolism: Signals and multiple effectors converge upon MMP-13 regulation in osteoarthritis. Eur Cell Mater 21: 202-220, 2011

22. Tang J, Cui W, Song F, Zhai C, Hu H, Zuo Q and Fan W: Effects of mesenchymal stem cells on interleukin-1 $\beta$-treated chondrocytes and cartilage in a rat osteoarthritic model. Mol Med Rep 12: 1753-1760, 2015.

23. Fricton JR and Schiffman EL: Reliability of a craniomandibular index. J Dent Res 65: 1359-1364, 1986.
24. Dominici M,Le Blanc K, Mueller I, Slaper-Cortenbach I, Marini F, Krause D, Deans R, Keating A, Prockop Dj and Horwitz E: Minimal criteria for defining multipotent mesenchymal stromal cells. The International Society for Cellular Therapy position statement. Cytotherapy 8: 315-317, 2006

25. Keating A: Mesenchymal stromal cells: New directions. Cell Stem Cell 10: 709-716, 2012.

26. Yoshimura H, Muneta T, Nimura A, Yokoyama A, Koga H and Sekiya I: Comparison of rat mesenchymal stem cells derived from bone marrow, synovium, periosteum, adipose tissue, and muscle. Cell Tissue Res 327: 449-462, 2007.

27. Ogata Y, Mabuchi Y, Yoshida M, Suto EG, Suzuki N, Muneta T, Sekiya I and Akazawa C: Purified human synovium mesenchymal stem cells as a good resource for cartilage regeneration. PLoS One 10: e0129096, 2015.

28. Suzuki S, Muneta T, Tsuji K, Ichinose S, Makino H, Umezawa A and Sekiya I: Properties and usefulness of aggregates of synovial mesenchymal stem cells as a source for cartilage regeneration. Arthritis Res Ther 14: R136, 2012.

29. Ritchlin C: Fibroblast biology. Effector signals released by the synovial fibroblast in arthritis. Arthritis Res 2: 356-360, 2000.

30. Kaneyama K, Segami N, Nishimura M, Suzuki T and Sato J Importance of proinflammatory cytokines in synovial fluid from 121 joints with temporomandibular disorders. Br J Oral Maxillofac Surg 40: 418-423, 2002.

31. Guttridge DC, Mayo MW, Madrid LV, Wang CY and Baldwin AS Jr: NF-kappaB-induced loss of MyoD messenger RNA: Possible role in muscle decay and cachexia. Science 289: 2363-2366, 2000.

32. Li X and Makarov SS: An essential role of NF-kappaB in the 'tumor-like' phenotype of arthritic synoviocytes. Proc Natl Acad Sci USA 103: 17432-17437, 2006.

33. Sitcheran R, Cogswell PC and Baldwin AS Jr: NF-kappaB mediates inhibition of mesenchymal cell differentiation through a posttranscriptional gene silencing mechanism. Genes Dev 17: 2368-2373, 2003.

34. Augello A, Tasso R, Negrini SM, Cancedda R and Pennesi G: Cell therapy using allogeneic bone marrow mesenchymal stem cells prevents tissue damage in collagen-induced arthritis. Arthritis Rheum 56: 1175-1186, 2007.

35. van Buul GM, Villafuertes E, Bos PK, Waarsing JH, Kops N, Narcisi R, Weinans H, Verhaar JA, Bernsen MR and van Osch GJ: Mesenchymal stem cells secrete factors that inhibit inflammatory processes in short-term osteoarthritic synovium and cartilage explant culture. Osteoarthritis Cartilage 20: 1186-1196, 2012.

36. Djouad F, Fritz V, Apparailly F, Louis-Plence P, Bony C, Sany J, Jorgensen C and Noël D: Reversal of the immunosuppressive properties of mesenchymal stem cells by tumor necrosis factor alpha in collagen-induced arthritis. Arthritis Rheum 52: $1595-1603,2005$.

37. Liu CH and Hwang SM: Cytokine interactions in mesenchymal stem cells from cord blood. Cytokine 32: 270-279, 2005.

38. Djouad F, Bony C, Häupl T, Uzé G, Lahlou N, Louis-Plence P, Apparailly F, Canovas F, Rème T, Sany J, et al: Transcriptional profiles discriminate bone marrow-derived and synoviumderived mesenchymal stem cells. Arthritis Res Ther 7: R1304-R1315, 2005.

39. Nishimura M, Segami N, Kaneyama K, Suzuki T and Miyamaru M: Proinflammatory cytokines and arthroscopic findings of patients with internal derangement and osteoarthritis of the temporomandibular joint. Br J Oral Maxillofac Surg 40: 68-71, 2002.

40. Fu K, Ma X, Zhang Z, Pang X and Chen W: Interleukin-6 in synovial fluid and HLA-DR expression in synovium from patients with temporomandibular disorders. J Orofac Pain 9: 131-137, 1995.

41. Roman-Blas JA and Jimenez SA: NF-kappaB as a potential therapeutic target in osteoarthritis and rheumatoid arthritis. Osteoarthritis Cartilage 14: 839-848, 2006. 